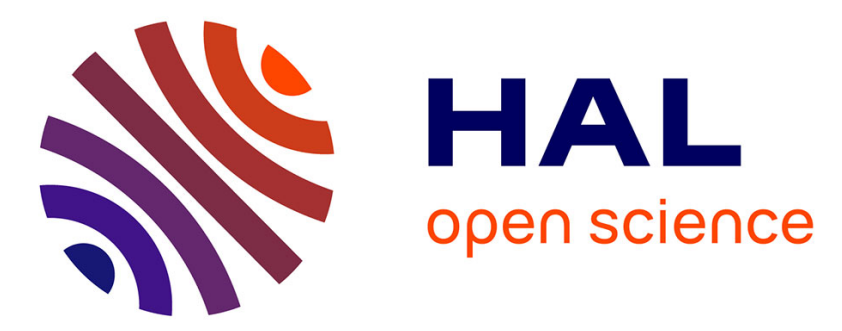

\title{
Electrochromatography on acrylate-based monolith in cyclic olefin copolymer microchip: A cost-effective and easy-to-use technology
}

Yoann Ladner, Gérard Crétier, Karine Faure

\section{- To cite this version:}

Yoann Ladner, Gérard Crétier, Karine Faure. Electrochromatography on acrylate-based monolith in cyclic olefin copolymer microchip: A cost-effective and easy-to-use technology. Electrophoresis, 2012, 33 (19-20), pp.3087-3094. 10.1002/elps.201200238 . hal-00799854

\section{HAL Id: hal-00799854 \\ https://hal.science/hal-00799854}

Submitted on 23 Jul 2020

HAL is a multi-disciplinary open access archive for the deposit and dissemination of scientific research documents, whether they are published or not. The documents may come from teaching and research institutions in France or abroad, or from public or private research centers.
L'archive ouverte pluridisciplinaire HAL, est destinée au dépôt et à la diffusion de documents scientifiques de niveau recherche, publiés ou non, émanant des établissements d'enseignement et de recherche français ou étrangers, des laboratoires publics ou privés. 
Electrochromatography on acrylate-based monolith in cyclic olefin copolymer microchip : a cost-effective and easy-to-use technology

Y. Ladner, G. Crétier, K. Faure

Université de Lyon

Institut des Sciences Analytiques (UMR Université Lyon 1 / CNRS : 5280)

Bâtiment Curien

Domaine université de La Doua

43 boulevard du 11 novembre 1918

F-69622 Villeurbanne cedex

France

\section{Keywords}

Electrochromatography / Acrylate-based monolith / COC microchip / Preconcentration

\section{Number of words}

\section{Abbreviations}

AMPS, 2-acrylamido-2-methyl-1-propanesulfonic acid; BDDA, 1,3-butanediol diacrylate; BME, benzoin methyl ether; COC, cyclic olefin copolymer; HA, hexyl acrylate; NDA, naphthalene-2,3dicarboxaldehyde; PEGMA, poly(ethyleneglycol) methacrylate 


\begin{abstract}
This paper shows that there is great interest in using an electrochromatographic microchip made of hexyl acrylate (HA)-based porous monolith cast within the channel of a cyclic olefin copolymer (COC) device. The monolith is simultaneously in-situ synthesized and anchored to the inner walls of the channel in less than $10 \mathrm{~min}$. By appropriate choice of light intensity used during the synthesis, the separation efficiency obtained for non-polar solutes such as polycyclic aromatic hydrocarbons (PAH) is increased up to 250000 plates $/ \mathrm{m}$. The performance of this HA-filled COC microchip was investigated for a wide range of analytes of varying nature. The reversed-phase separation of four aflatoxins is obtained in less than $2 \mathrm{~min}$. The baseline separation of a mixture of neurotransmitters including six amino acids and two catecholamines is possible thanks to the superimposition of the differences in electrophoretic mobility on the chromatographic process. The durability of the system at $\mathrm{pH} 13$ allows the separation of five biogenic amines and the quantitative determination of two of them in numerous wine samples. The feasibility of on-line preconcentration was also demonstrated. Hydrophilic surface modification of $\mathrm{COC}$ channel via UV-photografting with poly(ethylene glycol) methacrylate (PEGMA) before in-situ synthesis of HA, is necessary to reduce the adsorption of very hydrophobic solutes such as PAH during enrichment. The detection limit of fluoranthene is decreased down to less than $1 \mathrm{ppb}$ with a preconcentration of 4.5 hours on the HA-filled PEGMA functionalized COC microchip.
\end{abstract}




\section{Introduction}

As the field of micro-total analysis systems ( $\mu$ TAS) develops, the use of electroosmotic flow (EOF) to control fluid transport across the microfluidic device and the dominance of electrokinetic techniques in separations on microchips are general trends. From an engineering point of view, the application of a voltage across the separation device is much easier than the application of a pressure difference. So, zone electrophoresis (ZE) and micellar electrokinetic chromatography (MEKC) are the major separation modes commonly implemented in microchips. The main interest of MEKC is the efficient separation of both ionisable and neutral compounds. These techniques are performed in an open channel and the separation conditions can be changed in a simple and cost-effective manner i.e. by changing the electrolyte composition. However, the performances of these devices can be affected by hydrodynamic flows resulting from hydrostatic pressure generated by the liquid level difference between the reservoirs. The control of this problem is often difficult with the portable systems used for on-site analysis.

Electrochromatography $(\mathrm{EC})$ on a porous monolithic stationary phase prepared within the channels of the microsystem is an attractive alternative for on-chip separations. It combines the separation mechanisms of electrophoresis (differences in electrophoretic mobility for ionized analytes) and liquid chromatography (differences in specific interactions with the stationary phase for all solutes). The synthesis of the monolithic chromatographic bed is generally easy and rapid via free radical photopolymerisation. A wide variety of monomers is available to adjust the chemistry of the stationary phase to the targeted selectivity. The presence of the porous bed within the separation channel limits or even suppresses the flow effects consequent to a possible hydrostatic pressure in field portable devices.

Most electrochromatographic microchips filled with polymer monolith were composed of quartz or glass and were fabricated using a variety of expensive techniques (wet and dry etching, photolithography, electron beam lithography) which are borrowed from electronic industry and often require clean-room facilities. Because of the high cost of both the material and the production process, these devices are not disposable. Generally, the acrylate-based porous polymer monoliths cast in these glass chips shows very good chromatographic performances. High efficiencies were obtained for the separation of, on the one hand, polycyclic aromatic hydrocarbons (PAH) (200000 plates/m on average) [1], on the other hand, amino acids and bioactive peptides labelled with naphthalene-2,3dicarboaldehyde (NDA) for fluorescence detection (up to 600000 plates $/ m$ ) [2, 3]. It was also demonstrated that, by direct injection on the head of the stationary phase, these micro-systems can preconcentrate a wide variety of compounds and interesting signal enhancement factors can be achieved without decrease in efficiency [4, 5]. Implementation of controlled gradient elution conditions is possible for the separation of complex samples such as protein digests [6].

Thermoplastic materials such as cyclic olefin copolymer (COC) allow the fabrication of cost-effective and solvent-resistant devices. With these inexpensive materials, fast prototyping of new devices is possible by classical micromachining steps (milling, drilling, turning). Inexpensive and rapid technologies such as hot embossing and injection molding can be used to mass produced 
microsystems which could be single-used to eliminate the cross-contamination and sample carryover problems arising from multiple uses of the same system. Some studies deal with the development of $\mathrm{COC}$ electrochromatographic microchips using photopatterned acrylate-based monolithic stationary phases [7-10]. We showed that wall ruggedness was sufficient to hold a non-anchored monolith in a COC device used in EC without pressure, but separation efficiency remains poor (about 70000 plates $/ \mathrm{m}$ ) [7]. Anchoring of acrylate monolith inside the COC microchip channel performed by either UV-grafting before monolith synthesis (two-steps method) [8] or increasing the photoinitiator concentration in the polymerization mixture (one-step method) [9], allows improvement of electrochromatographic efficiency (up to 120000 plates $/ \mathrm{m}$ ). The achievement of efficiencies as high as the ones obtained in glass microchips for neutral solutes (200000 plates/m for PAH for example) requires the optimization of light intensity during photopolymerization [10].

The present paper illustrates the simplicity with which a COC electrochromatographic microchip can be used. The hexyl acrylate (HA)-based stationary phase is in situ photo-polymerized within a few minutes. Its robustness over a large range of mobile phase compositions and $\mathrm{pH}$ values allows various separations. The micro-system is shown to withstand a large number of injections of real samples such as wines. The possibility of performing preconcentration on the column head is evaluated for analytes of different hydrophobicities. This study demonstrates that the hydrophilic surface modification of $\mathrm{COC}$ channel walls is needed to preconcentrate non-polar solutes. The functionalization of native $\mathrm{COC}$ is then performed by photo-grafting with poly(ethylene glycol) methacrylate (PEGMA) before the in situ synthesis of HA-based monolith.

Each of these features has already been studied in glass chip but is here, to the best of our knowledge, presented for the first time in COC chip.

\section{Materials and methods}

\subsection{Chemicals, real samples and materials}

Hexyl acrylate (HA), poly(ethyleneglycol) methacrylate (PEGMA), 1,3-butanediol diacrylate (BDDA), 2acrylamido-2-methyl-1-propanesulfonic acid (AMPS) and benzoin methyl ether (BME) were obtained from Acros Organics (France). Naphthalene-2,3-dicarboxaldehyde (NDA), acetone, ammonium phosphate $\left(\mathrm{NH}_{4} \mathrm{H}_{2} \mathrm{PO}_{4}\right)$, lithium dodecyl sulphate (LiDS), orthophosphoric acid, sodium hydroxide, sodium cyanide, boric acid, sodium tetraborate, polycyclic aromatic hydrocarbons (PAH) (anthracene, fluoranthene and pyrene), aflatoxins (B1, B2, G1 and G2), biogenic amines (histamine, tyramine, tryptamine, putrescine and cadaverine), catecholamines (noradrenaline and dopamine) and amino acids (arginine, $y$-aminobutyric acid (GABA), serine, glycine, glutamic acid and aspartic acid) were from Sigma-Aldrich (France). Acetonitrile (ACN) and ethanol were HPLC-grade (SDS, France). Water was purified by a Purelab UHQ II system (Elga, France). Wine samples were purchased at local supermarkets. 
The microchips (1.5 cm $\times 9.5 \mathrm{~cm} \times 1.5 \mathrm{~mm}$ ) composed of COC (Topas ${ }^{\circledR} 6013$ ) and fabricated by Microfluidic Chipshop GmbH (Germany), exhibit only one $81 \mathrm{~mm}$-long, $75 \mu \mathrm{m}$-deep and $75 \mu \mathrm{m}$-wide channel.

\subsection{Instrumentation}

The system used to perform UV irradiations at $365 \mathrm{~nm}$ was a Bio-link cross linker (VWR International, France) equipped with five 8 W UV tubes. The light intensity illuminating the microchip was measured with an UV radiometer (Vilbert Lourmat, Germany). A gas chromatograph oven GC-17A (Shimadzu, Japan) was used to dry the $\mathrm{COC}$ microchip after hydrophilic modification. For mobile phase preparation, $\mathrm{pH}$ value is monitored in the aqueous part using a MeterLab pHmeter (Radiometer, France). For rinsing, injection and elution operations, electric fields generated by a $\mu$ TK high power supply (Micralyne, Canada) were applied to the microchannel through platinum electrodes placed in the reservoirs. Electrochromatographic separations were monitored by a IX-71 inverted fluorescence microscopic system (Olympus, France) equipped with a XF02-2 $100 \mathrm{~W}$ mercury lamp (Omega, USA) and an excitation filter of $330 \mathrm{~nm}$ (collection above $400 \mathrm{~nm}$ ) for PAH and aflatoxin detection or $405 \mathrm{~nm}$ (collection above $500 \mathrm{~nm}$ ) for NDA-labelled solutes (amino acids, catecholamines and biogenic amines). A CCD camera was combined with NI Vision software (Alliance Vision, France) for detection processing.

\section{3. in situ synthesis of monolith}

The monolith based on HA and BDDA monomers, was previously used in $\mathrm{COC}$ electrochromatographic microchips $[9,10]$. The porogenic mixture made of $54 \% \mathrm{w} / \mathrm{w}$ of $\mathrm{ACN}, 23 \%$ $\mathrm{w} / \mathrm{w}$ of ethanol and $23 \% \mathrm{w} / \mathrm{w}$ of water, is dissolved in the monomer mixture containing $66.4 \% \mathrm{w} / \mathrm{w}$ of $\mathrm{HA}$ and $33.6 \% \mathrm{w} / \mathrm{w}$ of BDDA, with the monomerto porogens ratio equal to $34.5: 65.5 \mathrm{w} / \mathrm{w}$. A charged monomer AMPS $(0.5 \% \mathrm{w} / \mathrm{w}$ of monomers) is added to generate a stable EOF. The concentration of the photoinitiator BME is fixed at $2.5 \%$ of monomers to allow the synthesis of organic monolith and its anchoring to the COC channel walls in one step [9]. After sonication for $15 \mathrm{~min}$, the polymerisation mixture is introduced in the micro-channel by pressure using a syringe. Then the microchip is placed in the $365 \mathrm{~nm}$ illumination system at $2.5 \mathrm{~cm}$ from the UV tubes. In this position, the microchip is irradiated with a light intensity of $4.7 \mathrm{~mW} / \mathrm{cm}^{2}$, which is optimal for the chip used [10]. After an irradiation of $6 \mathrm{~min}$ (which corresponds to an energy of $1.9 \mathrm{~J} / \mathrm{cm}^{2}$ ), the monolith present in the reservoirs is scraped away. Then, the channel filled with the HA-based monolith is rinsed with ACN/water 70:30 (v/v) $+2 \mathrm{mM}$ $\mathrm{NH}_{4} \mathrm{H}_{2} \mathrm{PO}_{4}+5 \mathrm{mM}$ LiDS by applying an electric field of $620 \mathrm{~V} / \mathrm{cm}$ for $30 \mathrm{~min}$ to remove any remaining reagent. When not in use, the HA-filled COC microchips are immersed in ethanol for conservation.

\subsection{Hydrophilic functionalization of COC channel walls}


In some experiments, the inner surface of the COC channel was modified with PEGMA before the synthesis of HA-based monolith within the channel. This functionalization was performed in a one step using a photo-grafting procedure [9]. The grafting solution is composed of $70 \mu \mathrm{L}$ of acetone, $30 \mu \mathrm{L}$ of $100 \mathrm{mM}$ PEGMA solution (prepared in water) and $2.5 \% \mathrm{w} / \mathrm{w}$ of BME. The reagent mixture is introduced in the micro-channel by pressure using a syringe and illumination with $365 \mathrm{~nm}$ UV light at an intensity of $1.7 \mathrm{~mW} / \mathrm{cm}^{2}$ (the microchip is placed at $15 \mathrm{~cm}$ from the light source)) is carried out for $20 \mathrm{~min}$ (which corresponds to an energy of $1.9 \mathrm{~J} / \mathrm{cm}^{2}$ ). Then the micro-channel is rinsed with ethanol using a syringe to remove any remaining reagent. Finally, the microchip is placed in the oven to dry the microchannel under $30^{\circ} \mathrm{C}$ for 1 hour before synthesis of the HA-based monolith.

\subsection{Procedure of derivatization with NDA}

The derivatization protocol was adapted from a previous work [11]. $50 \mu \mathrm{L}$ of $100 \mathrm{mM} \mathrm{pH} 9$ borate solution (prepared by mixing $500 \mathrm{mM}$ boric acid solution and $125 \mathrm{mM}$ sodium tetraborate solution to obtain $\mathrm{pH}$ 9), $50 \mu \mathrm{L}$ of $43 \mathrm{mM} \mathrm{NaCN}$ solution (prepared in water) and $250 \mu \mathrm{L}$ of $2.5 \mathrm{mM}$ NDA solution (prepared in ACN/water 50/50 v/v) are successively added to $100 \mu \mathrm{L}$ of sample (wine or aqueous solution of neurotransmitters or biogenic amines). Then the mixture is rapidly shaken and the reaction is allowed to proceed at ambient temperature for 4 min before injection.

\subsection{Electrochromatographic separations}

Sample injection in the separation channel was performed by using the simple direct injection procedure introduced in a previous publication [7]. A few microliters of sample are placed in the inlet reservoir. The outlet reservoir is filled with mobile phase. To introduce the solutes in the separation channel, an electric field of $125 \mathrm{~V} / \mathrm{cm}$ is applied for a given time. This injection time is varied in a wide range: from $1 \mathrm{~s}$ for normal injections to $16400 \mathrm{~s}$ for experiments with extreme preconcentration. The inlet reservoir is then fully washed with the mobile phase and, finally, an electric field of $620 \mathrm{~V} / \mathrm{cm}$ is applied for separation. The separation length, i.e. the distance between the inlet reservoir and the detection point, is specified for each experiment. LiDS is systematically added in mobile phases to improve the wettability of HA monolith with mobile phase containing high content of water. Adsorption of the surfactant on the surface of stationary phase decreases the surface tension at the interface solid-liquid, which avoids stationary phase drying and subsequent current instability. This mechanism was reported to make easier EC analysis on particles columns [12, 13].

\subsection{Wine analysis}

Histamine and tyramine contents of wines were determined by spiking each wine with a known concentration of the target analytes. For each analysis of wine, the procedure is as follows: the microchip is first rinsed with $\mathrm{ACN} /$ water $70: 30(\mathrm{v} / \mathrm{v})+2 \mathrm{mM} \mathrm{NH}_{4} \mathrm{H}_{2} \mathrm{PO}_{4}+5 \mathrm{mM} \mathrm{LiDS}$ under $620 \mathrm{~V} / \mathrm{cm}$ 
for $10 \mathrm{~min}$. The unspiked and spiked wine samples are derivatized with NDA. Three injections of each wine sample (spiked or not) are performed to evaluate histamine and tyramine concentrations.

\section{Results and discussion}

\subsection{Separation of different classes of solutes}

The performances of HA-filled COC microchips for the reversed-phase separation of six PAH (anthracene, fluoranthene, pyrene, benzo-a-anthracene, benzo-a-pyrene and benzo-k-fluoranthene) were characterized elsewhere [10]. It was shown that, with a mobile phase containing $70 \% \mathrm{ACN}$, the retention factors of solutes were contained between 5.2 and 17.8 and efficiencies ranged from 200000 to 250000 plates $/ \mathrm{m}$ at a linear velocity of $1.6 \mathrm{~mm} / \mathrm{s}$ for a separation length of $2 \mathrm{~cm}$ (the corresponding time analysis was $3.5 \mathrm{~min}$ ). Moreover microchip-to-microchip reproducibility was quite satisfactory since the mean relative standard deviation for EOF, retention factors and efficiencies were $10 \%, 8 \%$ and $6 \%$, respectively.

The usefulness of HA-filled $\mathrm{COC}$ microchips was further evaluated in separating a mixture of four aflatoxins. The development of a simple, rapid and cheap analytical procedure of these toxic compounds is important because European Union has fixed the maximum permitted levels (a few nanograms per gram) in agricultural products such as corn, peanuts, cotton seed and tree nuts [14]. Using a hydro-organic mobile phase containing $70 \%$ water, the four aflatoxins were separated within $1.7 \mathrm{~min}$ on a $7 \mathrm{~cm}$ separation length affording an average theoretical plate count of 34000 per meter (Figure 1). Their order of elution which is $\mathrm{G} 2, \mathrm{G1}, \mathrm{B} 2$ and $\mathrm{B} 1$, is identical to the one observed in reversed-phase liquid chromatography [15]. Using HA stationary phase, $70 \%$ water content is required in the mobile phase to separate the critical pair of $\mathrm{G} 1$ and B2 aflatoxins (solutes 2 and 3). A possible explanation for the relatively low separation efficiency obtained could be the slow mass transfer between stagnant and mobile zones in the column, when it is used with very aqueous mobile phase [16]. However it was also observed that peak broadening on acrylate monolithic column is strongly dependent on the type and functionality of the solutes $[16,17]$.

Unlike neutral solutes whose separation is solely based on chromatographic partitioning between stationary and mobile phases, ionisable solutes such as amino acid and catecholamines can be separated on the basis of the differences between both their electrophoretic mobilities and their interactions with stationary phase. The performance of HA-filled COC microchip for this separation type was evaluated with a mixture of neurotransmitters composed of five amino acids (arginine,, serine, glycine, glutamic acid and aspartic acid), GABA ( $\gamma$-aminobutyric acid) and two catecholamines (noradrenaline and dopamine). The determination of these solutes in small samples such as brain microdialysates is important to understand various neuro-physiological processes [18]. For fluorescence detection, the primary amine function of the different solutes was off-line labelled with NDA before injection and the baseline separation of the eight solutes was obtained at $\mathrm{pH}=4$ in about 
$3.5 \mathrm{~min}$ on a separation length of $7 \mathrm{~cm}$ with an efficiency ranging from 100000 to 330000 plates $/ \mathrm{m}$ (Figure 2A). Various $\mathrm{pH}$ values between $\mathrm{pH} 2$ and $\mathrm{pH} 13$ have been tested and $\mathrm{pH} 4$ seems to offer the largest selectivity. Indeed, at this $\mathrm{pH}$ value, the NDA-derivatized catecholamines with pKa of their catechol function of about 6-7 are undissociated and can be considered as neutral. Their migration in HA monolith results totally from a chromatographic process. On the other hand, the carboxylic acid function of free alphaamino acids is nearly totally dissociated $(\mathrm{pKa}=2.1-2.4)$. So serine, glycine, glutamic acid and aspartic acid are anionic and an interplay between the electrophoretic and chromatographic processes controls their migration. Since the carboxylic function of GABA exhibits a pKa of 4.2, and the electrolyte is not buffered, its migration time can vary and special attention should be paid for the preparation and replenish of fresh mobile phase. With a pKa of 12.5 , the guanidinium group of arginine is positively charged and NDA-derivatized arginine is globally neutral. But its high polarity results in a low retention on HA monolith. With no electrophoretic mobility and weak chromatographic retention, NDA-derivatized arginine almost migrates with the electroosmotic flow. In the separation of neurotransmitters, the chromatographic process i.e. the interactions of solutes with monolith play a major part. Indeed, Figure $2 \mathrm{~B}$ shows that there is no separation with the used mobile phase in an open channel $\mathrm{COC}$ microchip i.e. a COC microchip without HA monolith. Therefore electrophoretic process on its own is not sufficient to separate these analytes. Electrochromatography offers here the ability to simultaneously separate neutral and charged compounds with a higher selectivity.

The performance of HA-filled COC microchip was also investigated for the determination of some biogenic amines in wines. The ingestion of histamine and tyramine can induce headaches in sensitive persons. Their formation has to be controlled during wine making. A portable glass microchip electrophoresis system was already used to monitor their concentration during the fermentation process [19] and we show here that the HA-filled COC microchip is usable for this control. Figure 3 shows the separation of five NDA-derivatized biogenic amines (histamine, tyramine, tryptamine, cadaverine and putrescine) performed at $70 \% \mathrm{ACN}, \mathrm{pH} 13$. As the derivatization of diamines (cadaverine and putrescine) is not total, the choice of $\mathrm{pH} 13$ prevents from the dissociation of the nonderivatized primary amine function ( $\mathrm{pKa}=10.2-10.8$ ) and reduces peak tailing due to electrostatic interactions between solutes and anionic stationary phase. The average efficiency was 125000 plates $/ \mathrm{m}$. Figures $4 \mathrm{~A}$ and $4 \mathrm{~B}$ show the representative electrochromatograms corresponding to the determination of histamine and tyramine concentrations in a red wine. The separation of the solutes of interest from the matrix is obtained by adapting the mobile phase to $60 \% \mathrm{ACN}$. By comparison of the electrochromatogram of the unspiked wine sample (Figure 4A) and the electrochromatogram of the wine sample spiked with $1.3 \mathrm{mg} / \mathrm{L}$ histamine and $1.9 \mathrm{mg} / \mathrm{L}$ tyramine (Figure 4B), the levels of histamine and tyramine in the analyzed red wine were evaluated at $0.2 \pm 0.03$ and $0.2 \pm 0.01 \mathrm{mg} / \mathrm{L}$, respectively. For confirmation, Figure $4 \mathrm{C}$ shows the injection of a standard solution containing histamine and tyramine at $1.3 \mathrm{mg} / \mathrm{L}$ and $1.9 \mathrm{mg} / \mathrm{l}$, respectively.

The durability of the HA-filled $\mathrm{COC}$ microchips was clearly confirmed during these experiments. Indeed, a wine sample is a complex mixture (particle, tannins, dyes ...) and was injected without 
filtration in the microchip. Since no pretreatment was applied, derivatization with NDA (specific of primary amines) led to numerous fluorescent species (amino acids, biogenic amines...). The obtained electrochromatograms containing numerous peaks were reproducible, with CV of $5 \%$ for retention factor, $8 \%$ for electroosmotic mobility and $4 \%$ for electrochromatographic efficiency, measured over 10 injections. Fifteen different wines (red wines and white wines) were analyzed on the same HA-filled COC microchip. This corresponds to about one hundred injections of real samples performed on the same microchip. Overall, the average lifetime of a microsystem was estimated to about 250 injections.

\subsection{On-line preconcentration}

The effect of water content of the sample matrix on the extent of preconcentration phenomenon in the HA-filled COC microchip was first studied with NDA-derivatized tyramine as model solute (Figure 5). The variations of peak height in function of corrected peak area (peak area divided by migration time) obtained for different injection times were studied when the sample matrix is identical to the mobile phase (Figure 5A) and less eluting than the mobile phase (Figure 5B). Each experimental point was repeated three times, with CV less than $8 \%$ on electroosmotic flow, migration time and peak area. When the sample solvent has the same composition as the mobile phase (70 $\mathrm{ACN} v / \mathrm{v})$, peak height variation is linear until an injection time of $10 \mathrm{~s}$. For larger injection times, peak height tends to level off because peak broadening occurs due to excessive injected volume. This injection time of $10 \mathrm{~s}$ offers the maximal sensitivity that can be reached when the sample is dissolved in mobile phase. Under these injection conditions, peak height is equal to $170 \mathrm{mV}$. When the sample matrix contains less eluting solvent than the mobile phase $(30 \% \mathrm{ACN} v / \mathrm{v})$, the peak height variation is linear until an injection time of $400 \mathrm{~s}$ This shows that no volume overload phenomenon occurs in this injection time range. Thus, by injecting the sample dissolved in a weakly eluting matrix ( $30 \% \mathrm{ACN} v / \mathrm{v}$ ) during $400 \mathrm{~s}$, peak reaches the height of $5820 \mathrm{mV}$, which corresponds to sensitivity 34 times larger than the maximal sensitivity obtained with the sample dissolved in mobile phase. Above 400 s injection time, the curve is almost linear up to $900 \mathrm{~s}$ injection time (which is the largest injection time tested in this experiment). This slight deviation from linearity may not be due to sample overloading but to degradation in the fluorescence signal of the solute. The study could not be conducted further on, as the fluorescent derivatives of tyramine-NDA are not stable over more than $30 \mathrm{~min}$.

The same study was undertaken with fluoranthene as model solute (Figure 6). Figure 6A shows that the height of fluoranthene peak does not increase with increasing injection time when the sample matrix is identical to mobile phase. As this behaviour was not observed with a more polar solute such as tyramine (Figure 5A), we suppose that it could originate from the hydrophobicity of fluoranthene and the possible adsorption of fluoranthene on COC channel walls. In order to verify this hypothesis, the same experiments were performed on a COC microchip of which the channel was functionalized with PEGMA before in situ synthesis of HA monolith. It was checked that this wall chemical modification had no impact on the electrochromatographic values (retention, EOF, efficiency). The results obtained with this HA-filled PEGMA-functionalized COC microchip were in agreement with expectation (Figure 6B): there is a range of injection time (until $40 \mathrm{~s}$ ) within which peak height 
increases proportionally to peak area and consequently no peak broadening occurs. With the maximal injection time of $40 \mathrm{~s}$, the peak height is equal to $0.43 \mathrm{mV}$. Hydrophilic surface modification of COC channel also allows implementation of very long preconcentration operation when the sample matrix has a lower eluting force than the mobile phase. Figure $6 \mathrm{C}$ shows the variation of peak height versus corrected peak area when fluoranthene is injected in $30 \% \mathrm{ACN} v / \mathrm{v}$ sampling phase and eluted with $70 \% \mathrm{ACN} v / \mathrm{v}$ mobile phase. The range of injection time investigated was very wide, up to $16200 \mathrm{~s}$ (4.5 hours) and no peak broadening was observed. With the injection time of $16200 \mathrm{~s}$, the peak height is equal to $57 \mathrm{mV}$. This allows an increase of 133 in sensitivity compared with injection of fluoranthene dissolved in mobile phase. Figure 7 presents the electrochromatogram obtained for the separation of three PAH using these conditions, i.e. a mobile phase containing $70 \% \mathrm{v} / \mathrm{v} \mathrm{ACN}$, a sample matrix containing $30 \% \mathrm{ACN} v / \mathrm{v}$ and an injection time of $16200 \mathrm{~s}$. After this very long preconcentration step, the separation is still satisfactory. The efficiencies (ranging from 100000 to 125000 plates $/ \mathrm{m}$ ) are kept high, even if they are decreased compared with those obtained with a normal injection of $5 \mathrm{~s}$ (200000 - 250000 plates $/ \mathrm{m}$ ). Low levels of PAH can be detected. The signal-to-noise ratios obtained for anthracene, fluoranthene and pyrene injected at 3.5, 0.5 and $15 \mathrm{ppb}$ are 11.5, 3.8 and 2.0, respectively Of course, the same results could be obtained in a shorter time by increasing the injection electrical field. However, when working with elevated electrical field for a long time, risks may arise from highly conductive samples and drying monoliths, reducing the microsystem lifetime.

\section{Concluding remarks}

The present investigation shows that HA-filled COC microchips are promising tools for field portable analysis. They offer many interesting features such as low cost, ease and rapidity of fabrication, simplicity of use, resistance to aggressive conditions (organic solvents, extreme $\mathrm{pH}$ ), application to a wide range of analytes (non-polar or polar, neutral or charged), high separation efficiency and ability for on-line preconcentration. 


\section{References}

[1] Fintschenko, Y., Choi, W-E, Ngola, S. M., Shepold, T. J., Fres. J. Anal. Chem. 2001, 371, 174181.

[2] Shediac, R., Ngola, S. M., Throckmorton, D. J., Anex, D. S., Shepold, T. J., Singh, A. K., J. Chromatogr. A 2001, 925, 251-263.

[3] Trockmorton, D. J., Shepold, T. J., Singh, A. K., Anal. Chem. 2002, 74, 784-789.

[4] Augustin, V., Proczek, G., Dugay, J., Descroix, S., Hennion, M-C, J. Sep. Sci. 2007, 30, 28582865.

[5] Proczek, G., Augustin, V., Descroix, S., Hennion, M-C., Electrophoresis 2009, 30, 515-524.

[6] Watson, M. W., Mudrik, J. M., Wheeler, A. R., Anal. Chem. 2009, 81, 3851-3857.

[7] Ladner, Y., Cretier, G., Faure, K., J. Chromatogr. A 2010, 1217, 8001-8008.

[8] Faure, K., Albert, M., Dugas, V., Cretier, G., Ferrigno, R., Morin, P., Rocca, J-L., Electrophoresis 2008, 29, 4948-4955.

[9] Ladner, Y., Bruchet, A., Cretier, G., Dugas, V., Randon, J., Faure, K., Lab Chip 2012, 12, 1680-1685.

[10] Ladner, Y., Cretier, G., Faure, K., J. Sep. Sci., accepted.

[11] Robert, F., Bert, L., Denoroy, L., Renaud, B., Anal. Chem. 1995, 67, 1838-1844.

[12] Ping, G., Zhang, W., Zhang, L., Schmitt-Kopplin, P., Zhang, Y., Kettrup, A., Chromatographia 2003, 57, 629-633.

[13] Valette, J-C., Bizet, A. C., Demesmay, C., Rocca, J-L., Verdon, E., J. Chromatogr. A, 2004, 1049, 171-181.

[14] Commission Regulation (EC) 1525/98, Off. J. Eur. Communities 1998, L 201, 43-46.

[15] Sobolev, S. V., J. Agric. Food Chem. 2007, 55, 2136-2141. 
[16] Huo, Y., Schoenmakers, P. J., Kok, W. T., J. Chromatogr. A 2007, 1175, 81-88.

[17] Eeltink, S., Rozing, G. P., Shoenmakers, P. J., Kok, W. T., J. Chromatogr. A 2006, 1109, 7479 .

[18] Parrot, S., Sauvinet, V., Riban, V., Depaulis, A., Renaud, B., Denoroy, L., J. Neurosci. Methods 2004, 140, 29-38.

[19] Jayarajah, C. N., Skelley, A. M., Fortner, A. D., Mathies, R. A., Anal. Chem. 2007, 79, 81628169. 


\section{Figure captions}

Figure 1: Separation of four aflatoxins in HA-filled $\mathrm{COC}$ microchip. Solutes (injected concentration) : 1 = aflatoxin $\mathrm{G} 2(1.2 \mu \mathrm{M}), 2$ = aflatoxin $\mathrm{G} 1(2.3 \mu \mathrm{M})$, aflatoxin $\mathrm{B} 2(4.8$ $\mu \mathrm{M}), 4$ = aflatoxin B1 $(23 \mu \mathrm{M})$. Mobile phase: ACN/water 30:70 (v/v) $+2 \mathrm{mM}$ $\mathrm{NH}_{4} \mathrm{H}_{2} \mathrm{PO}_{4}+5 \mathrm{mM}$ LiDS. Separation length: $7 \mathrm{~cm}$. Injection time: $10 \mathrm{~s}$. Electrical field $620 \mathrm{~V} / \mathrm{cm}$.

Figure 2: Separation of eight neurotransmitters labelled with NDA in (A) HA-filled COC microchip and $(B)$ open channel $\operatorname{COC}$ microchip. Solutes : $1=$ arginine, $2=$ noradrenaline, $3=$ GABA, 4 = serine, 5 = glycine, $6=$ glutamic acid, $7=$ aspartic acid, 8 = dopamine. Mobile phase : ACN/water 50:50 (v/v) $+2 \mathrm{mM} \mathrm{NH}_{4} \mathrm{H}_{2} \mathrm{PO}_{4}+5 \mathrm{mM}$ LiDS, $\mathrm{pH}$ adjusted to 4 with $\mathrm{H}_{3} \mathrm{PO}_{4}$. Separation length : $7 \mathrm{~cm}$. Injected concentration of each solute : $120 \mu \mathrm{M}$. Injection time : $10 \mathrm{~s}$. Electrical field $620 \mathrm{~V} / \mathrm{cm}$.

Figure 3: Separation of five biogenic amines labelled with NDA in HA-filled COC microchip. Solutes : 1 = histamine, 2 = putrescine, $3=$ cadaverine, $4=$ tyramine, $5=$ tryptamine. Mobile phase : ACN/water 70:30 (v/v) $+2 \mathrm{mM} \mathrm{NH}_{4} \mathrm{H}_{2} \mathrm{PO}_{4}+5 \mathrm{mM} \mathrm{LiDS}-\mathrm{pH}$ adjusted to 13 with $\mathrm{NaOH}$. Separation length : $7 \mathrm{~cm}$. Injected concentration of each solute : 0.2 $\mathrm{mM}$. Injection time : $10 \mathrm{~s}$. Electrical field $620 \mathrm{~V} / \mathrm{cm}$.

Figure 4: $\quad$ Analysis of NDA-derivatized biogenic amines : (A) unspiked wine sample and (B) wine sample spiked with $1.3 \mathrm{mg} / \mathrm{L}$ histamine and $1.9 \mathrm{mg} / \mathrm{L}$ tyramine. (C) mixture of standards with $1.3 \mathrm{mg} / \mathrm{L}$ histamine and $1.9 \mathrm{mg} / \mathrm{L}$ tyramine. Solutes : $1=$ histamine, $2=$ tyramine. Mobile phase : ACN/water 60:40 (v/v) $+2 \mathrm{mM} \mathrm{NH}_{4} \mathrm{H}_{2} \mathrm{PO}_{4}+5 \mathrm{mM} \mathrm{LiDS}-\mathrm{pH}$ adjusted to 13 with $\mathrm{NaOH}$. Separation length : $7 \mathrm{~cm}$. Injection time : $20 \mathrm{~s}$. Electrical field $620 \mathrm{~V} / \mathrm{cm}$.

Figure 5: Preconcentration of NDA-derivatized tyramine on HA-filled COC microchip : variations of peak height versus corrected peak area (the value placed close to each experiment point states the corresponding injection time). Sample matrix : (A) ACN/water 70:30 (v / v) $+2 \mathrm{mM} \mathrm{NH}_{4} \mathrm{H}_{2} \mathrm{PO}_{4}+5 \mathrm{mM}$ LiDS - pH 13 , (B) ACN/water 30:70 (v/ v) $+2 \mathrm{mM}$ $\mathrm{NH}_{4} \mathrm{H}_{2} \mathrm{PO}_{4}+5 \mathrm{mM}$ LiDS $-\mathrm{pH}$ 13. Mobile phase : ACN/water 70:30 (v/ v) $+2 \mathrm{mM}$ $\mathrm{NH}_{4} \mathrm{H}_{2} \mathrm{PO}_{4}+5 \mathrm{mM}$ LiDS $-\mathrm{pH} 13$. Separation length : $3.5 \mathrm{~cm}$. Injected concentration : 2 $\mu \mathrm{M}$. Electrical field $620 \mathrm{~V} / \mathrm{cm}$.

Figure 6: Preconcentration of fluoranthene on (A) HA-filled COC microchip and (B, C) HA-filled PEGMA-functionalized COC microchip : variations of peak height versus corrected peak area (the value placed close to each experiment point states the corresponding 
injection time. Sample matrix : (A, B) ACN/water 70:30 (v/v) $+2 \mathrm{mM} \mathrm{NH}_{4} \mathrm{H}_{2} \mathrm{PO}_{4}+5$ $\mathrm{mM}$ LiDS, (C) ACN/water 30:70 (v/v) $+2 \mathrm{mM} \mathrm{NH}_{4} \mathrm{H}_{2} \mathrm{PO}_{4}+5 \mathrm{mM}$ LiDS . Mobile phase : ACN/water 70:30 (v/v) $+2 \mathrm{mM} \mathrm{NH}_{4} \mathrm{H}_{2} \mathrm{PO}_{4}+5 \mathrm{mM}$ LiDS. Separation length : $3.5 \mathrm{~cm}$. Injected concentration : $1 \mathrm{ppb}$. Electrical field $620 \mathrm{~V} / \mathrm{cm}$.

Figure 7: Preconcentration and separation of three PAH on HA-filled PEGMA-functionalized $\mathrm{COC}$ microchip. Solutes (injected concentration) : $1=$ anthracene $(3.5 \mathrm{ppb}), 2=$ fluoranthene $(0.5 \mathrm{ppb}), 3=$ pyrene $(15 \mathrm{ppb})$. Mobile phase : ACN/water 70:30 (v/v) +2 $\mathrm{mM} \mathrm{NH} \mathrm{H}_{2} \mathrm{PO}_{4}+5 \mathrm{mM}$ LiDS. Sample matrix : ACN/water 30:70 (v/v) $+2 \mathrm{mM}$ $\mathrm{NH}_{4} \mathrm{H}_{2} \mathrm{PO}_{4}+5 \mathrm{mM}$ LiDS . Separation length : $3.5 \mathrm{~cm}$. Injection time : $16200 \mathrm{~s}(4.5$ hours). Electrical field $620 \mathrm{~V} / \mathrm{cm}$. 

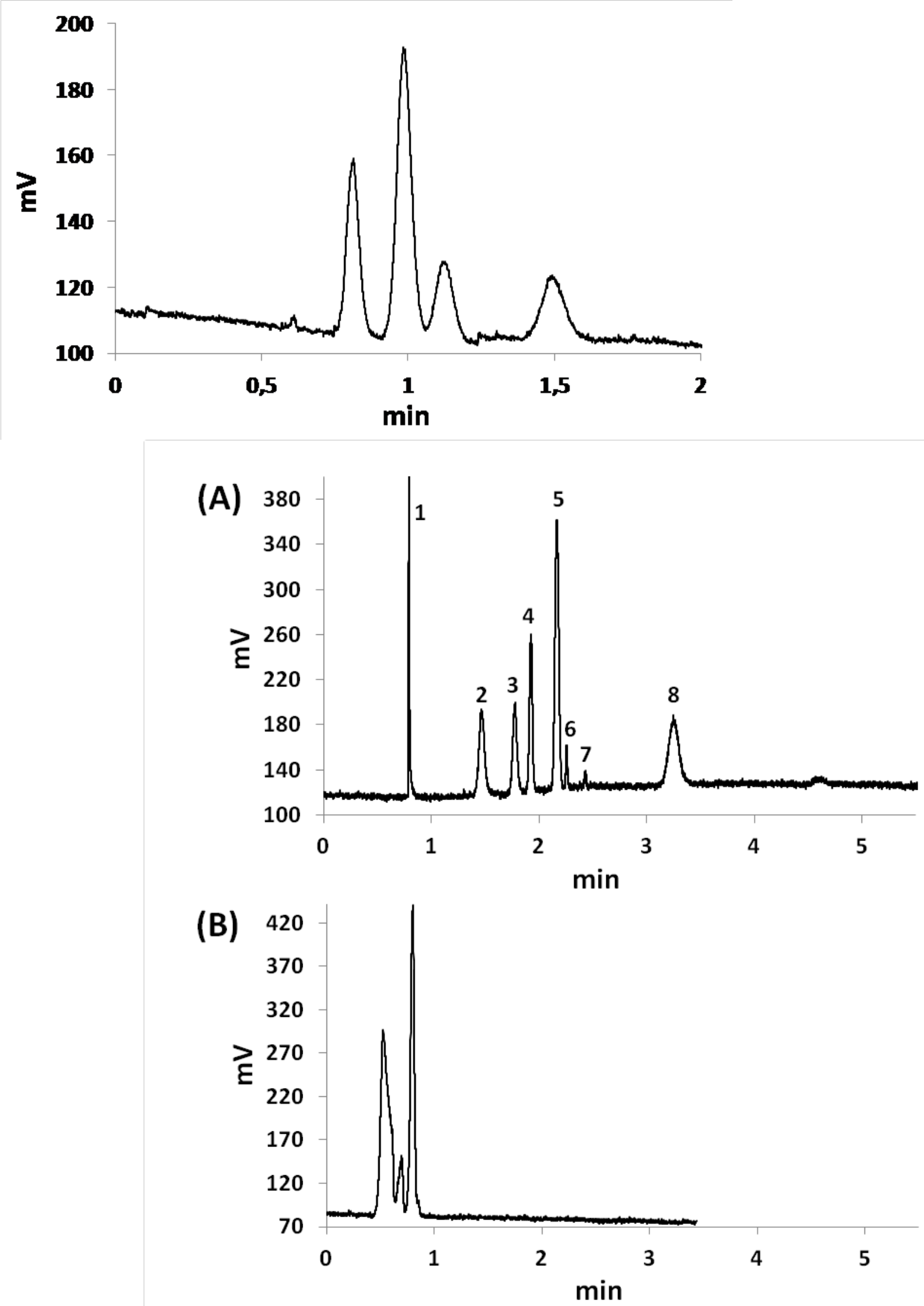


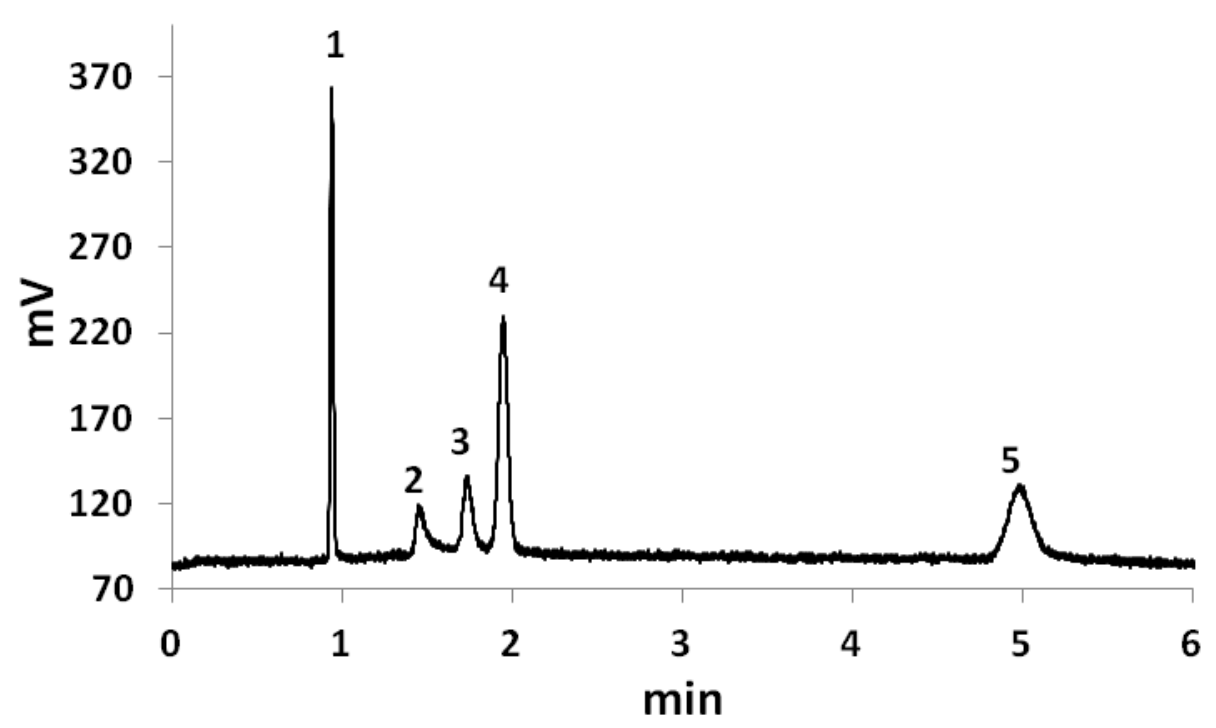



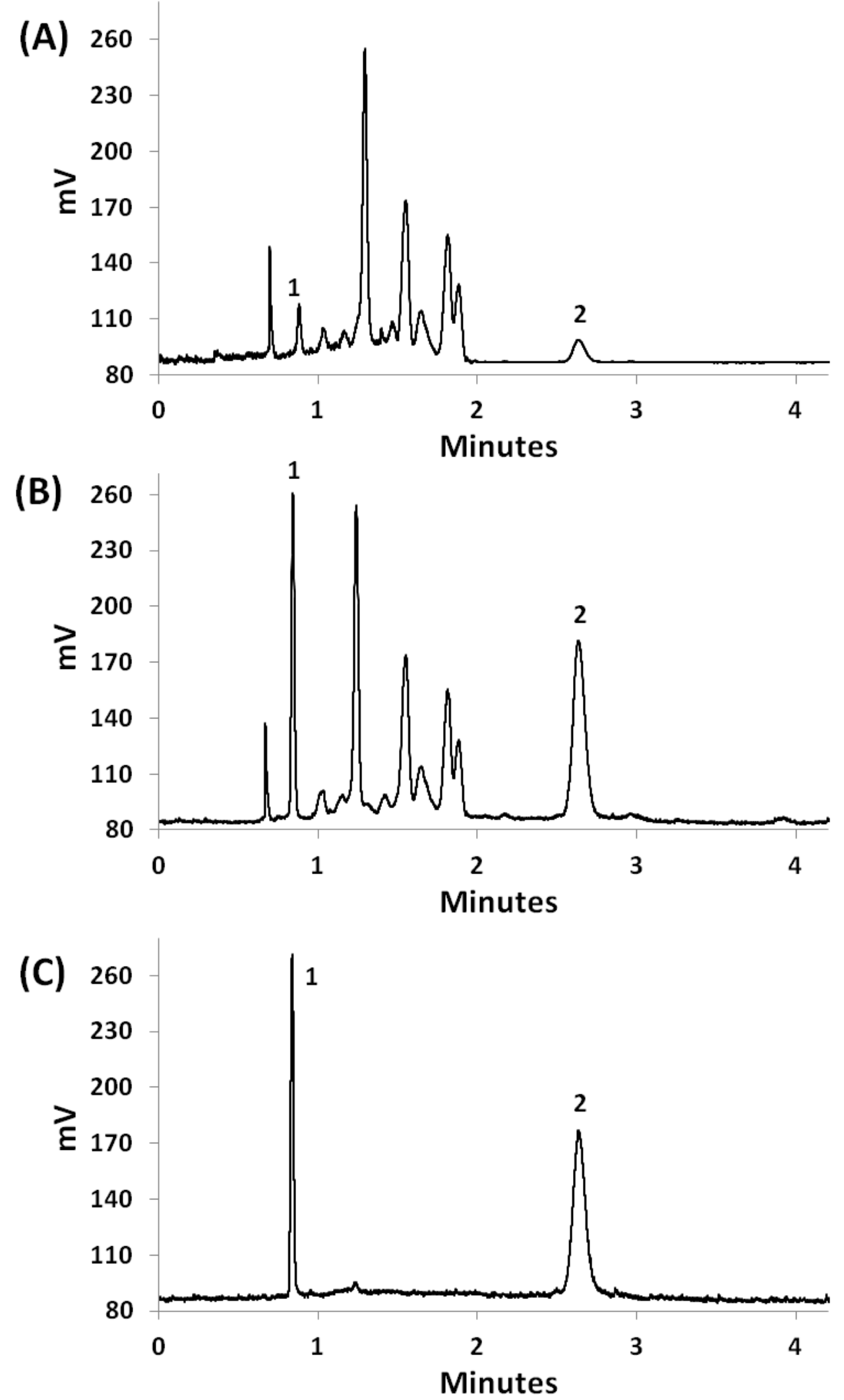

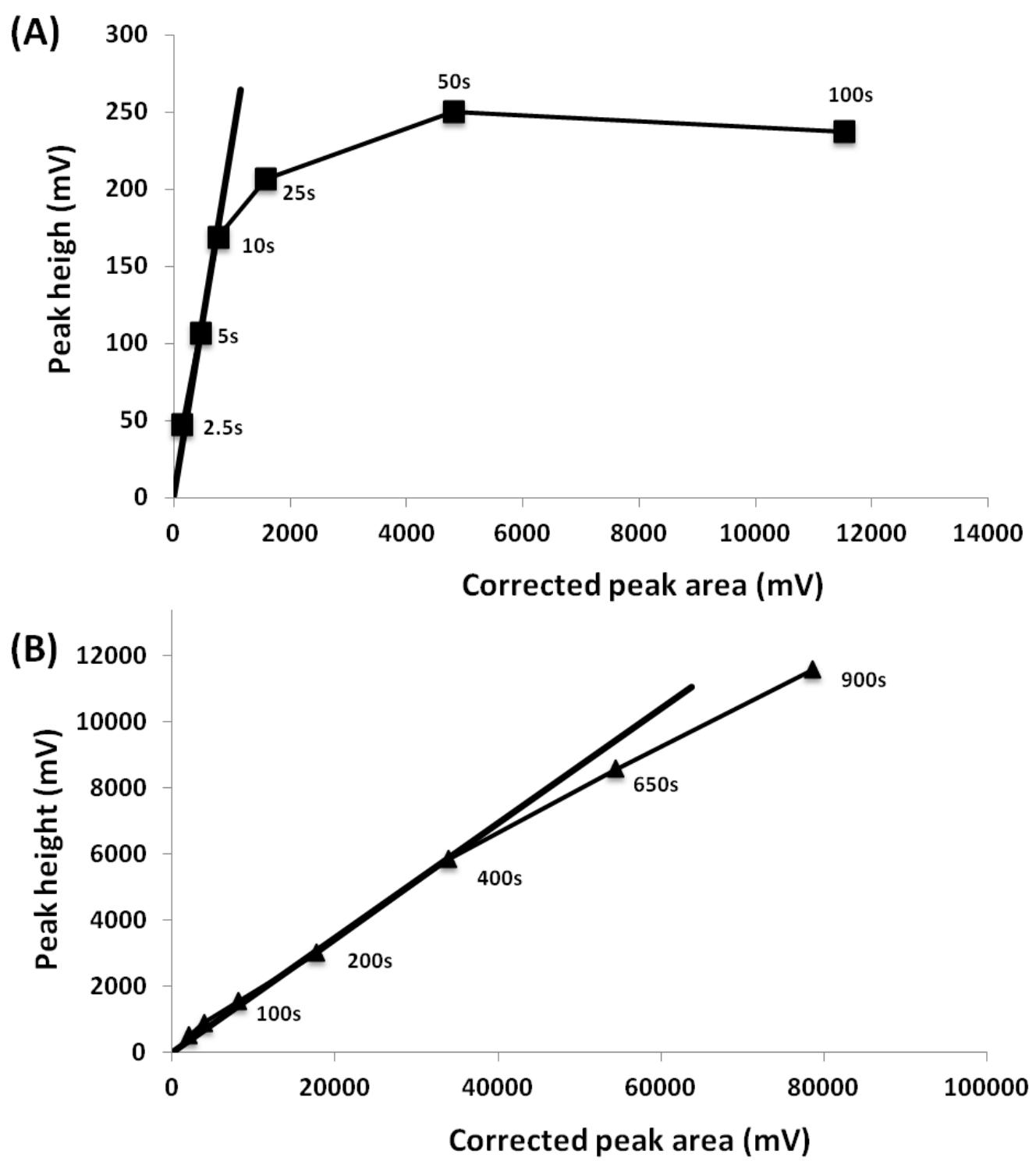

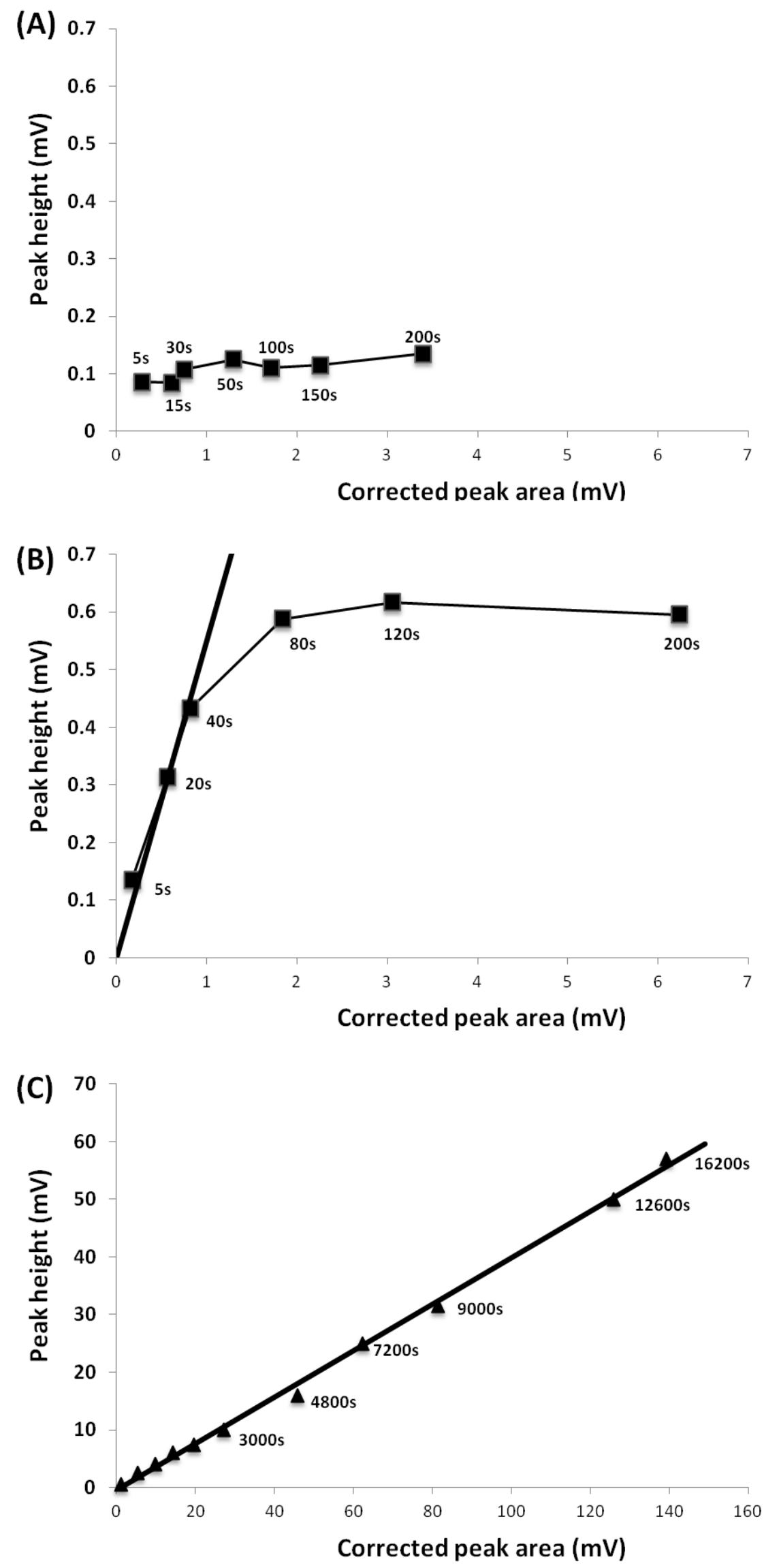


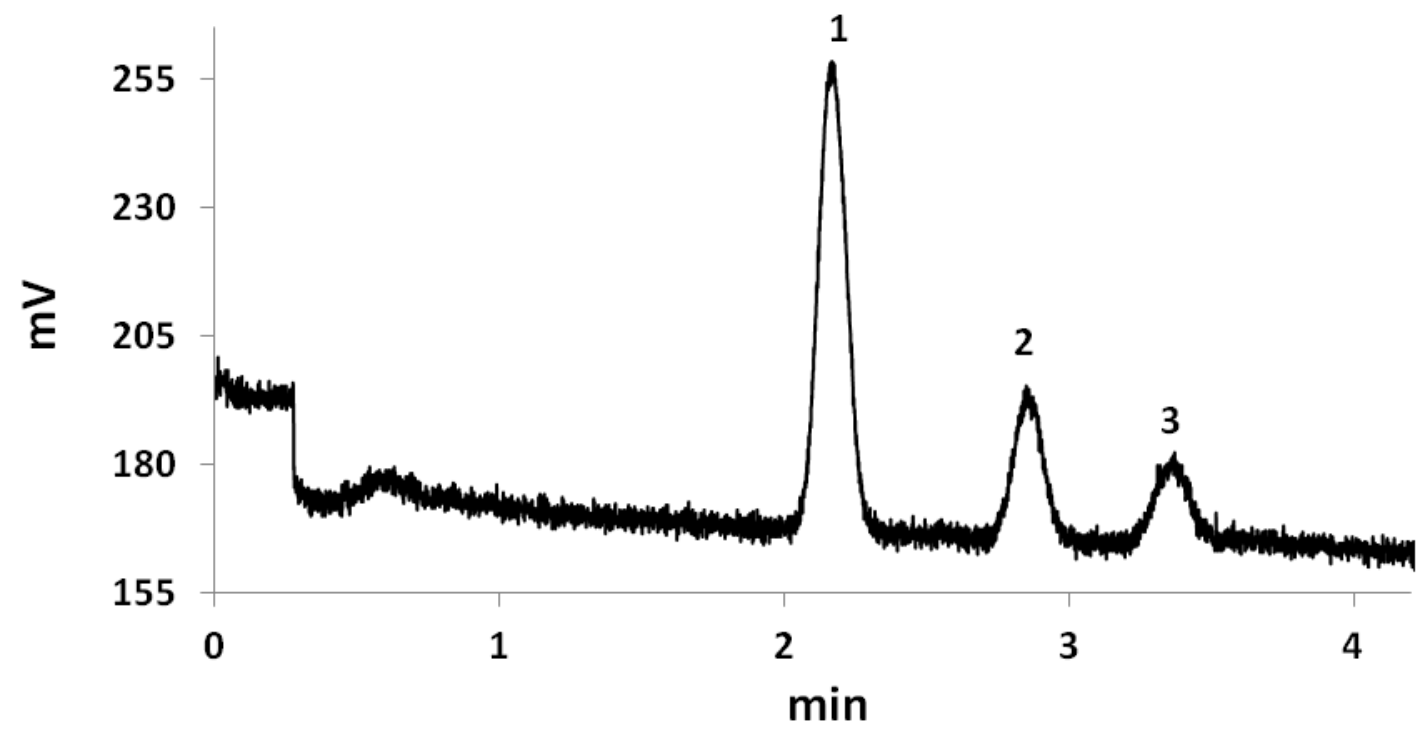

